\title{
Routine detection of hyperketonemia in dairy cows using Fourier transform infrared spectroscopy analysis of $\beta$-hydroxybutyrate and acetone in milk in combination with test-day information
}

\author{
S. G. A. van der Drift, ${ }^{, 1}$ R. Jorritsma, ${ }^{*}$ J. T. Schonewille, ${ }^{*}$ H. M. Knijn, $\dagger$ and J. A. Stegeman* \\ ${ }^{*}$ Department of Farm Animal Health, Faculty of Veterinary Medicine, Utrecht University, PO Box 80151, 3508 TD Utrecht, the Netherlands \\ †Cattle Improvement Cooperative (CRV) BV, PO Box 454, 6800 AL Arnhem, the Netherlands
}

\begin{abstract}
The objective of this study was to assess the quality of a diagnostic model for the detection of hyperketonemia in early lactation dairy cows at test days. This diagnostic model comprised acetone and $\beta$-hydroxybutyrate (BHBA) concentrations in milk, as determined by Fourier transform infrared (FTIR) spectroscopy, in addition to other available test-day information. Plasma BHBA concentration was determined at a regular test day in 1,678 cows between 5 and $60 \mathrm{~d}$ in milk, originating from 118 randomly selected farms in the Netherlands. The observed prevalence of hyperketonemia (defined as plasma $\mathrm{BHBA} \geq 1,200 \mu \mathrm{mol} / \mathrm{L}$ ) was $11.2 \%$. The value of FTIR predictions of milk acetone and milk BHBA concentrations as single tests for hyperketonemia were found limited, given the relatively large number of false positive test-day results. Therefore, a multivariate logistic regression model with a random herd effect was constructed, using parity, season, milk fat-to-protein ratio, and FTIR predictions of milk acetone and milk BHBA as predictive variables. This diagnostic model had $82.4 \%$ sensitivity and $83.8 \%$ specificity at the optimal cutoff value (defined as maximum sum of sensitivity and specificity) for the detection of hyperketonemia at test days. Increasing the cutoff value of the model to obtain a specificity of $95 \%$ increased the predicted value of a positive test result to $56.5 \%$. Confirmation of test-positive samples with wet chemistry analysis of milk acetone or milk BHBA concentrations (serial testing) improved the diagnostic performance of the test procedure. The presented model was considered not suitable for individual detection of cows with ketosis due to the length of the test-day interval and the low positive predictive values of the investigated test procedures. The diagnostic model is, in our opinion, valuable for herd-level monitoring of hyperketonemia, especially when the model is combined with wet chemistry analy-
\end{abstract}

Received April 5, 2011.

Accepted May 24, 2012.

${ }^{1}$ Corresponding author: sgavanderdrift@gmail.com sis of milk acetone or milk BHBA concentrations. By using the diagnostic model in combination with wet chemistry milk BHBA analysis, $84 \%$ of herds were correctly classified at a $10 \%$ alarm-level prevalence. As misclassification of herds may particularly occur when only a limited number of fresh cows are sampled, we suggest using prevalence estimates over several consecutive test days to evaluate feeding and management practices in smaller dairy farms.

Key words: hyperketonemia, acetone, $\beta$-hydroxybutyrate, test-day milk

\section{INTRODUCTION}

Monitoring metabolic disorders in early lactation is increasingly used to evaluate transition cow management and to guide strategies to improve health and fertility on dairy farms. Subclinical ketosis or hyperketonemia is considered one of the key metabolic disorders in dairy cows (Oetzel, 2004; LeBlanc, 2010), because it increases the risk for clinical ketosis (Dohoo and Martin, 1984; Seifi et al., 2011) and other disorders such as displaced abomasum (Geishauser et al., 1997; LeBlanc et al., 2005; Duffield et al., 2009). Hyperketonemia was also found to be associated with reduced reproductive performance (Andersson et al., 1991; Walsh et al., 2007). The prevalence of subclinical ketosis can vary largely between individual farms (Dohoo and Martin, 1984), but average prevalences of 12.0 to $14.1 \%$ have been reported (Nielen et al., 1994; Duffield et al., 1997; Geishauser et al., 2000). An alarm-level prevalence of $10 \%$ has been suggested when testing herds for ketosis (Oetzel, 2004).

Subclinical ketosis is defined by an increased concentration of ketone bodies in body fluids in the absence of clinical signs (Andersson, 1988). Analysis of the concentration of BHBA in blood is considered the reference test to diagnose hyperketonemia in dairy cows. Previous studies have used thresholds of 1,200 (Nielen et al., 1994; Duffield et al., 1997) to $1,400 \mu \mathrm{mol} / \mathrm{L}$ (Geishauser et al., 2000; Oetzel, 2004) to differentiate between cows with and without hyperketonemia. More 
recently, Duffield et al. (2009) showed that increased health risk and reduced milk production indeed started when blood BHBA concentrations exceeded either 1,200 or $1,400 \mu \mathrm{mol} / \mathrm{L}$, depending on the stage of lactation. Several cowside tests have been validated for the detection of ketone bodies in blood (Iwersen et al., 2009), milk (e.g., Jorritsma et al., 1998), or urine (e.g., Carrier et al., 2004), but practical limitations frequently do not allow for routine testing of all animals at risk at regular intervals. Therefore, several attempts have been made to validate in-line methods for routine analysis of the ketone body acetone in milk, such as flow injection analysis (Gustafsson and Emanuelson, 1996) and Fourier transform infrared (FTIR) spectroscopy (Hansen, 1999; Heuer et al., 2001). de Roos et al. (2007) assessed an FTIR spectroscopy calibration for routine milk analysis of BHBA in addition to acetone. van Knegsel et al. (2010) compared such FTIR predictions of BHBA and acetone in test-day milk samples with plasma BHBA concentrations from an experimental group of cows. They concluded that FTIR predictions of milk BHBA and acetone could detect hyperketonemia with a higher accuracy than milk fat-to-protein ratio. Therefore, routine milk ketone body analysis should be considered for herd monitoring at test days. Limitations of the use of milk acetone or milk BHBA as a single test (i.e., the relatively large proportion of false-positive results; van Knegsel et al., 2010) might be reduced by designing a diagnostic model for test days that also includes additional test-day information of cows.

The objective of this study was to assess the quality of a diagnostic model comprising the concentration of acetone and BHBA in milk, as determined by FTIR spectroscopy, and available test-day information for the detection of hyperketonemia in early lactation dairy cows. It was also investigated whether hyperketonemia detection in cows could be improved by additional wet chemistry analysis of acetone and BHBA in selected test-day milk samples (serial testing) compared with the use of test-day information alone.

\section{MATERIALS AND METHODS}

\section{Farm and Animal Selection}

The present experiment was evaluated and approved by the Ethical Committee on Animal Experiments from Utrecht University (Utrecht, the Netherlands). From November 2009 to November 2010, 1,772 cows of various parities from 123 dairy farms in the Netherlands were enrolled in the study. Farms were randomly selected from the milk recording database of the Cattle Improvement Cooperative (CRV BV, Arnhem, the Netherlands) organization, which includes $83.8 \%$ of all Dutch dairy farmers. Farms with robotic milking were excluded from the study, as it was not possible to standardize the interval between milk and blood sampling. Herds with fewer than 50 dairy cows were also excluded, as well as farms where test-day sampling was performed by the farmer instead of a qualified employer from the milk-recording company. Farms were visited once at a regular test day and all cows between 5 and 60 DIM that participated in the milk recording were included in the study. The window from 5 to 60 DIM was considered as the high-risk period for hyperketonemia. Farm visits were equally distributed over the year.

\section{Sampling Protocol and Sample Analysis}

To ensure the practical applicability of the study results, test-day milk sampling and milk sample analysis were all performed according to the standard milkrecording procedures in practice. None of the researchers was, therefore, present during test-day sampling. In the Netherlands, test-day sampling is performed in the evening of a certain day and the consecutive morning of the next day. Farms were visited on the same day as the morning test-day sampling and blood samples were drawn from all eligible cows between 1100 and $1400 \mathrm{~h}$ for plasma analysis of BHBA (reference test). Blood samples were drawn from the coccygeal vein into evacuated heparinized tubes. Blood samples were centrifuged at the same day at $2,800 \times g$ for $10 \mathrm{~min}$ and plasma was separated and frozen at $-20^{\circ} \mathrm{C}$ until analysis. Plasma samples were analyzed for BHBA in a routine laboratory using a Randox test kit (Ranbut kit; Randox Laboratories Ltd., Crumlin, UK). The milk composition of all test-day samples was analyzed according to regular test-day procedures in the laboratory of Qlip NV (Zutphen, the Netherlands). Briefly, test-day milk samples were gently preheated to $40^{\circ} \mathrm{C}$ and mixed before analysis with a MilkoScan FT600 (Foss Analytical A/S, Hillerød, Denmark). This FTIR instrument was used according to the instructions of the manufacturer with operational calibrations for fat (ISO 1211, IDF1; ISO, 1999), protein (ISO 8968, IDF 20-1; ISO, 2001), and BHBA and acetone (de Roos et al., 2007). After completion of test-day analysis, acetone and BHBA concentrations in milk samples were also determined by chemical analysis (segmented flow methods), as described by de Roos et al. (2007).

\section{Data Analysis}

Cow records were excluded from further analysis in case of incorrect stage of lactation $(<5$ or $>60$ DIM $)$ at sampling $(\mathrm{n}=18)$, unknown calving date $(\mathrm{n}=4)$, missing test-day results $(n=10)$, or analytical errors in 
FTIR test-day milk results $(\mathrm{n}=62)$. The final analysis was performed with 1,678 cow records from 118 farms.

A threshold of $\geq 1,200 \mu \mathrm{mol} / \mathrm{L}$ was used in the present study as a diagnostic reference to identify cows with hyperketonemia. Mean plasma BHBA concentrations were calculated for different parities, stages of lactation (DIM), and seasons. Differences in plasma BHBA concentrations between these categories were analyzed using Kruskal-Wallis rank sum tests followed by post hoc pairwise Wilcoxon rank sum tests. Additionally, prevalences of hyperketonemia were calculated and differences between categories were analyzed using proportions tests with pairwise comparisons of proportions with Bonferroni correction for multiple comparisons.

The potential diagnostic value of FTIR predictions for the detection of hyperketonemia was first investigated by evaluating the performance of milk BHBA and milk acetone as single tests. The accuracy of milk acetone or milk BHBA as single-test variables was assessed by producing receiver operating characteristic (ROC) curves and calculating the area under the curve (AUC). The optimal cutoff value for each test variable was defined as that cut point where sensitivity plus specificity were at a maximum (i.e., equal weighing of false-positive and false-negative test results). Subsequently, predictive values (as for the prevalence of hyperketonemia in this study) were calculated at this cutoff value for each test variable.

To construct the optimal diagnostic model, several variables were combined into a multivariate logistic regression model, using a cutoff value for plasma BHBA concentration of $\geq 1,200 \mu \mathrm{mol} / \mathrm{L}$ to define hyperketonemia. Only test-day variables that are currently available were considered as predictive variables for construction of this model. Parity, number of DIM (both recoded into categories), and season were investigated as categorical variables. Continuous test-day variables eligible for the multivariate model were milk production, difference between the actual and expected milk production, projected 305-d production, milk fat content, milk protein content, milk fat-to-protein ratio, milk acetone (FTIR) content, and milk BHBA (FTIR) content. Expected test-day milk production and projected 305-d production are routinely estimated by the milk-recording company with prediction models, using the individual milk production potential of the cow, given her previous test-day results and previous lactations, and the average lactation curve of cows from a similar age, calving season, and herd.

Potentially predictive variables for the multivariate diagnostic model were first selected based on univariate logistic regression analysis, using $P<0.25$ as the selection criterion. For the categorical variables, the Wald test was additionally used to test for an overall effect; to compare the different categories, odds ratios were calculated from the coefficients of the univariate logistic regression model of each categorical variable. Subsequently, a multivariate logistic regression model was constructed with the generalized linear mixed model procedure, starting with the model including all selected test-day variables as fixed effects. A random herd effect (random intercept per herd) was incorporated in the model to control for potential clustering of cows within herd. Model parameters were estimated with the maximum likelihood method (Laplace approximation). Stepwise, backward model reduction was performed by excluding variables with a $P$-value $>0.10$ from the model using Akaike's information criterion (AIC) as the selection criterion. The final multivariate logistic regression model was checked (visual inspection) by plotting the deviance residuals against the fitted values for all observations. Pearson correlation coefficients between the variables milk acetone and milk BHBA, milk acetone and milk fat-to-protein ratio, and milk BHBA and milk fat-to-protein ratio in this data set were $0.72,0.49$, and 0.51 , respectively. Presence of collinearity in the model was checked by examining the standard errors of the regression coefficients and by checking whether regression coefficients of these variables reflected the positive association with hyperketonemia observed in the univariate regression analysis. Additionally, milk acetone, milk BHBA, and milk fat-to-protein ratio were one by one removed from the model to evaluate the effect of each variable to the model. It was concluded that no (multi)collinearity was present in the model.

Although random herd effects were used for the model selection to correct for within-herd clustering of cows, these random herd effects were removed from the model, when its performance as a test for hyperketonemia was evaluated. The reason for this was that these effects will be unknown when the model is applied to other herds. Therefore, fitted values of cows were calculated using only the fixed terms of the diagnostic model. These fitted values were subsequently applied as a single-test variable and the accuracy of the model for the detection of hyperketonemia (defined as plasma BHBA $\geq 1,200 \mu \mathrm{mol} / \mathrm{L}$ ) was evaluated by producing the ROC curve and calculating the AUC. The AUC of the model was compared with the AUC of the single-test variables milk acetone or milk BHBA using the DeLong test for correlated ROC curves (Robin et al., 2011). The optimal cutoff value for the model was defined as the cut point where sensitivity plus specificity were at a maximum and predictive values (as for the prevalence in this study) were calculated at this cutoff value. Ranges of observed plasma BHBA concentrations for each of the test result categories (i.e., true negative, 
false positive, false negative, and true positive) were shown in a box plot. Differences between these categories were analyzed using Kruskal-Wallis rank sum tests, followed by post hoc pairwise Wilcoxon rank sum tests. Additionally, the sensitivity and positive predictive value (given the prevalence in this study) of the diagnostic model were assessed when the applied cutoff value was arbitrarily increased until the model reached a specificity of 90 or $95 \%$, respectively.

Addition of a second test (serial testing) increases the specificity of a test procedure. In the Netherlands, routine wet chemistry analysis of acetone and BHBA concentrations could be performed in test-day milk samples that tested positive in FTIR spectroscopy analysis. To evaluate the diagnostic value of this serial test procedure, milk samples that were classified as test positive with the diagnostic model at the optimal cutoff value (test 1 ) were retested by chemical analysis of milk acetone or milk BHBA (test 2). To this end, all cows classified as test positive at the optimal cutoff value of the diagnostic model were included in a separate derivative data set. Thus, this derivative data set contained only the true-positive and false-positive test outcomes for the model (test 1) at this cutoff value. Subsequently, the optimal cutoff value (maximum sum of sensitivity and specificity) for chemically analyzed milk acetone or milk BHBA (test 2) to detect hyperketonemia in cows in this derivative data set were assessed by constructing ROC curves. Single-test outcomes for chemically analyzed milk acetone and BHBA were then combined with the test results from the diagnostic model to calculate the overall sensitivity, specificity, and predictive values of the serial test procedures. For these serial test procedures, cows were classified as having hyperketonemia when they were tested positive with the diagnostic model and when the milk acetone or milk BHBA concentration analyzed by wet chemistry analysis was above the cutoff value. Chemical analysis of milk acetone and milk BHBA in all test-day samples would not be feasible in practice (too expensive and time consuming) and this option was, therefore, not investigated in the present study.

The performance of the diagnostic model for herdlevel testing was evaluated by herd-level comparisons of the true prevalence of hyperketonemia, as assessed by plasma BHBA concentrations, and the apparent prevalence, as estimated by the diagnostic model with and without the serial-test procedure. Proportions of correctly estimated, underestimated, and overestimated herd prevalences were calculated. A herd prevalence of above $10 \%$ has been previously suggested as alarm-level prevalence when 12 of all fresh cows between 5 and 50 DIM are sampled (Oetzel, 2004). Although circumstances for our study were different, as we sampled all cows between 5 and 60 DIM at the test day, we used this suggested alarm level illustratively to calculate the number of incorrectly notified healthy farms (i.e., prevalence of $10 \%$ or below) and the number of missed problem herds (i.e., prevalence above 10\%) with our diagnostic model. The value of the diagnostic model for herd monitoring was assessed at the optimal cutoff value of the model, at the cutoff values where the specificity of the model was 90 or $95 \%$, and when applied in combination with wet chemical analysis of milk acetone or BHBA concentrations.

Construction of ROC curves and calculations on sensitivity and specificity at selected cutoff values were performed with statistical package SPSS (version 16.0 for Windows; SPSS Inc., Chicago, IL). Sensitivity, specificity, and predictive values (including confidence intervals) at a certain cutoff value of single tests and diagnostic models were calculated using Win Episcope 2.0 (Thrusfield et al., 2001). All other data analyses were done with statistical Package $\mathrm{R}$ (version 2.9.1; R Foundation for Statistical Computing, Vienna, Austria).

\section{RESULTS}

Cows enrolled in the data analysis $(\mathrm{n}=1,678)$ produced, on average (mean \pm SD), $35.7 \pm 8.3 \mathrm{~kg}$ of milk with a fat content of $4.34 \pm 0.77 \%$ and a protein content of $3.28 \pm 0.32 \%$ at the test day. The average prevalence of hyperketonemia on included dairy farms was $11.2 \%$, whereas individual farm prevalences ranged from 0 to $80.0 \%$. Plasma BHBA concentrations and prevalences of hyperketonemia for different parities, stages of lactation, and seasons are shown in Table 1. Mean plasma BHBA concentration increased with increasing parity $(P<0.05)$; prevalences of hyperketonemia were lower in cows from parity 1 or 2 compared with cows from higher parities $(P<0.05)$. Mean plasma BHBA concentrations were higher in cows between 5 and 30 DIM than in cows between 31 and 60 DIM $(P<0.05)$; the prevalence of hyperketonemia was highest in cows between 5 and 10 DIM and decreased significantly $(P$ $<0.05)$ to a prevalence below $10 \%$ in cows between 31 and 60 DIM. Mean plasma BHBA concentrations and prevalences of hyperketonemia were higher in cows sampled in spring (March to May) and summer (June to August) than in cows sampled in winter (December to February) or fall (September to November; $P<$ $0.05)$.

Receiver operating characteristic curves for milk acetone (FTIR predictions) and milk BHBA (FTIR predictions) as single-test variables for hyperketonemia are shown in Figure 1. For each test variable, the area under the ROC curve, and sensitivity, specificity, and 
Table 1. Plasma BHBA concentrations, proportions of cows with hyperketonemia (threshold $\geq 1,200 \mu \mathrm{mol} / \mathrm{L}$ ), and odds ratios for presence of hyperketonemia at the test day from univariate logistic regression analysis for different parities, stages of lactation, and seasons of 1,678 cows from 118 Dutch dairy farms

\begin{tabular}{|c|c|c|c|c|c|}
\hline \multirow[b]{2}{*}{ Item } & \multirow{2}{*}{$\begin{array}{l}\text { Number } \\
\text { of cows }\end{array}$} & \multicolumn{2}{|c|}{$\begin{array}{c}\text { Plasma BHBA } \\
(\mu \mathrm{mol} / \mathrm{L})\end{array}$} & \multirow{2}{*}{$\begin{array}{c}\text { Proportion above } \\
\text { threshold }(\%)\end{array}$} & \multirow{2}{*}{$\begin{array}{l}\text { Odds ratio } \\
(95 \% \mathrm{CI})\end{array}$} \\
\hline & & Mean & SD & & \\
\hline All cows & 1,678 & 752 & 526 & 11.2 & - \\
\hline \multicolumn{6}{|l|}{ Parity } \\
\hline 1 & 446 & $618^{\mathrm{d}}$ & 358 & $5.6^{\mathrm{c}}$ & $\operatorname{Ref}^{1}$ \\
\hline 2 & 455 & $654^{\mathrm{c}}$ & 326 & $5.3^{\mathrm{c}}$ & $0.94(0.52-1.67)$ \\
\hline 3 & 326 & $806^{\mathrm{b}}$ & 541 & $12.9^{\mathrm{b}}$ & $2.49(1.50-4.23)$ \\
\hline 4 or higher & 451 & $944^{\mathrm{a}}$ & 721 & $21.5^{\mathrm{a}}$ & $4.61(2.95-7.46)$ \\
\hline \multicolumn{6}{|l|}{ DIM } \\
\hline $5-10$ & 104 & $918^{\mathrm{a}}$ & 470 & $22.1^{\mathrm{a}}$ & Ref \\
\hline $11-20$ & 307 & $834^{\mathrm{b}}$ & 642 & $16.3^{\mathrm{a}, \mathrm{b}}$ & $0.68(0.40-1.21)$ \\
\hline $21-30$ & 308 & $839^{\mathrm{b}}$ & 632 & $15.6^{\mathrm{a}, \mathrm{b}}$ & $0.65(0.38-1.15)$ \\
\hline $31-40$ & 327 & $728^{b, c}$ & 511 & $9.5^{\mathrm{b}, \mathrm{c}}$ & $0.37(0.20-0.67)$ \\
\hline $41-50$ & 350 & $671^{\mathrm{c}}$ & 442 & $6.0^{\mathrm{c}}$ & $0.22(0.12-0.43)$ \\
\hline $51-60$ & 282 & $634^{\mathrm{c}}$ & 305 & $5.3^{\mathrm{c}}$ & $0.20(0.10-0.39)$ \\
\hline \multicolumn{6}{|l|}{ Season } \\
\hline Fall & 445 & $627^{\mathrm{b}}$ & 392 & $7.4^{\mathrm{b}}$ & Ref \\
\hline Winter & 474 & $667^{\mathrm{b}}$ & 447 & $8.0^{\mathrm{b}}$ & $1.09(0.67-1.78)$ \\
\hline Spring & 353 & $867^{\mathrm{a}}$ & 562 & $14.7^{\mathrm{a}}$ & $2.15(1.37-3.45)$ \\
\hline Summer & 406 & $887^{\mathrm{a}}$ & 644 & $16.0^{\mathrm{a}}$ & $2.38(1.54-3.74)$ \\
\hline
\end{tabular}

predictive values at the optimal cutoff value are presented in Table 2. Milk acetone and milk BHBA had a similar overall diagnostic accuracy. At the selected cutoff value, milk acetone had a higher specificity $(89.2$ vs. $76.0 \%)$ and milk BHBA had a higher sensitivity $(83.0$ vs. $70.7 \%)$. Due to the observed prevalence of ketosis in this study, positive predictive values were low for both tests.

The categorical variables parity, number of DIM, and season were all associated $(P<0.001)$ with the occurrence of hyperketonemia in dairy cows in early lactation. Odds ratios for the different categories of each variable are displayed in Table 1. Univariate logistic associations of the continuous variables with the presence of hyperketonemia are shown in Table 3. Milk production at the test day and the projected 305-d milk production were not associated with the presence or absence of hyperketonemia and were, thus, not further investigated in the multivariate diagnostic model. All other variables were significantly associated with the occurrence of the disease $(P<0.001)$. Cows with hyperketonemia had a lower-than-expected milk production compared with cows having plasma BHBA concentrations below the threshold. Also, cows with hyperketonemia produced milk with higher concentrations of fat, acetone, and BHBA and a lower protein content (higher fat-to-protein ratio). Although associated with the occurrence of hyperketonemia, the variables milk fat content or milk protein content did not significantly contribute to the final multivariate model.

The final diagnostic test-day model contained the variables parity, season, milk fat-to-protein ratio, milk acetone, and milk BHBA (Table 4). The ROC curve for fitted values of this model is also shown in Figure 1. The area under the ROC curve, the optimal cutoff value, and sensitivity, specificity, and predictive values at this cutoff value are presented in Table 2 . The AUC of the diagnostic model was larger than the AUC of milk acetone $(P<0.05)$ or milk BHBA $(P<0.01)$ applied as single-test variables.

At the observed prevalence of $11.2 \%$, the number of false-positive test results was high and positive predictive values were low for the model at the optimal cutoff value. Plasma BHBA concentrations of cows that were false positively or false negatively misclassified with the model were compared with those of correctly classified cows in Figure 2. Mean plasma BHBA concentrations in cows of these 4 categories differed from each other $(P<0.05)$. Mean plasma BHBA concentrations of misclassified cows were closer to the threshold value of $1,200 \mu \mathrm{mol} / \mathrm{L}$ than those of cows correctly classified as either ketotic of nonketotic. The test performance of the model was also evaluated at the (arbitrarily chosen) cutoff values where the specificity of the model equaled 90 or $95 \%$, respectively. The diagnostic model had a sensitivity of $69.7 \%(63.1-76.3 \%)$ and a positive predic- 
Table 2. Analysis of receiver operating characteristic (ROC) curves and test characteristics at optimal cutoff value (maximum sum of sensitivity and specificity) for milk acetone concentration, milk BHBA concentration, and fitted values from the logistic regression model based on available test-day information as test variables to detect hyperketonemia based on test-day results from 1,678 cows in early lactation (5-60 DIM)

\begin{tabular}{lccc}
\hline Item & Acetone & BHBA & Model \\
\hline ROC curve & & & \\
AUC $^{1}(\%)$ & 85.8 & 85.1 & 88.5 \\
SE & 1.6 & 1.5 & 1.4 \\
$95 \%$ CI & $82.7-89.0$ & $82.2-88.0$ & $85.8-91.1$ \\
Optimal cutoff value ( $\mu$ mol/L) & 131.5 & $\geq 76.3$ & 0.076 \\
Test characteristics (at optimal cutoff value) & & & \\
Sensitivity (\%) & 70.7 & 83.0 & 82.4 \\
95\% CI & $64.2-77.2$ & $77.6-88.4$ & $77.0-87.9$ \\
Specificity (\%) & 89.2 & 76.0 & 83.8 \\
95\% CI & $87.6-90.8$ & $73.8-78.1$ & $81.9-85.6$ \\
Positive predictive value (\%) & 45.2 & 30.4 & 39.0 \\
95\% CI & $39.5-50.9$ & $26.4-34.3$ & $34.2-43.8$ \\
Negative predictive value (\%) & 96.0 & 97.3 & 97.4 \\
$95 \%$ CI & $95.0-97.1$ & $96.3-98.2$ & $96.6-98.3$ \\
\hline
\end{tabular}

${ }^{1}$ Area under the curve.

tive value of $46.7 \%(40.9-52.6 \%)$ at the cutoff value (0.116) selected to obtain a specificity of $90 \%$. The diagnostic model had a sensitivity of $51.1 \%(43.9-58.2 \%)$ and a positive predictive value of $56.5 \%(49.0-63.9 \%)$ at the cutoff value $(0.222)$ selected to obtain a specificity of $95 \%$.

Cows classified as hyperketonemic (either true positive or false positive) with the model $(\mathrm{n}=397)$ at the

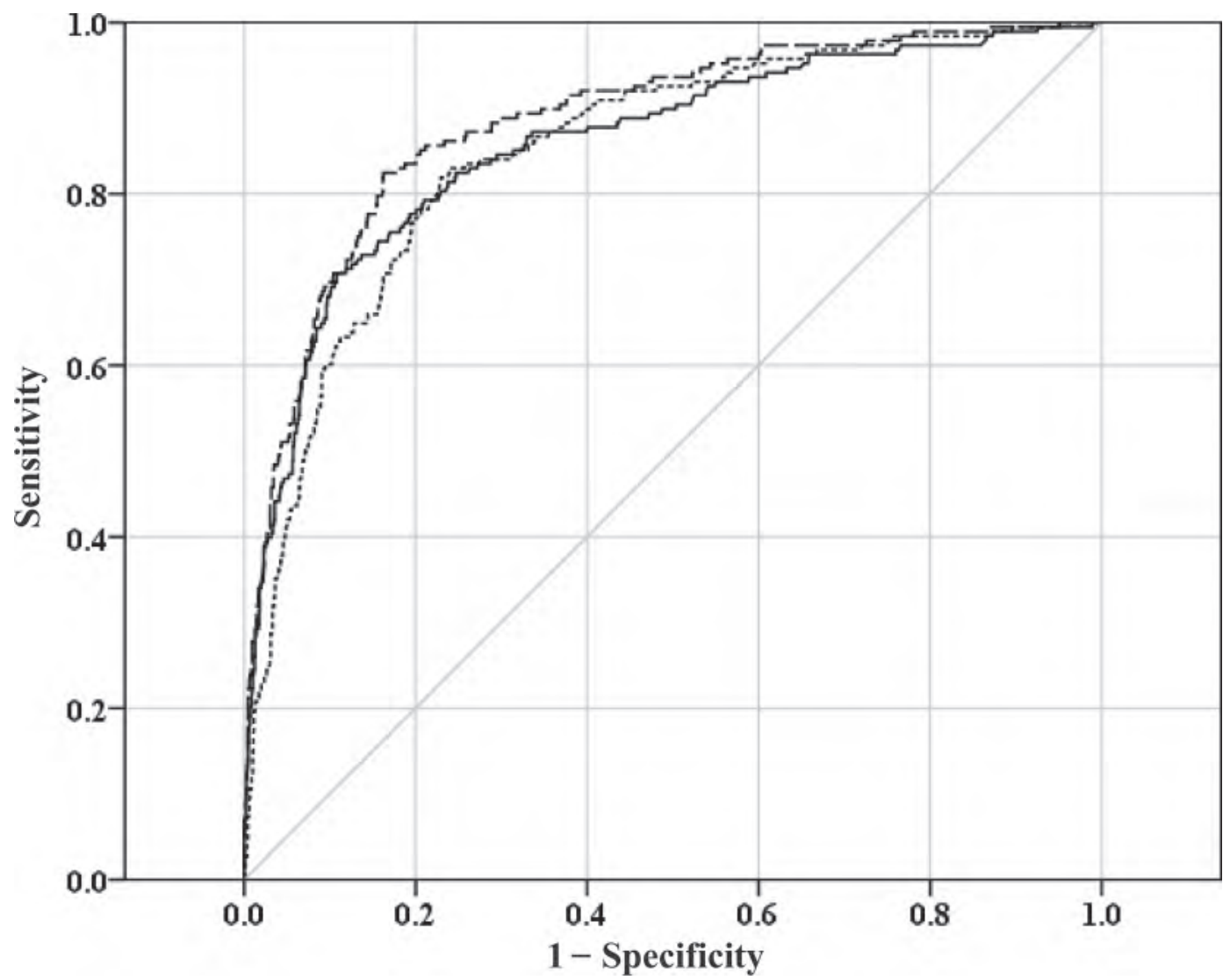

Figure 1. Receiver operating characteristic curves for milk acetone (solid line), milk BHBA (dotted line), and fitted values from the logistic regression model based on available test-day information (dashed line) as test variables for hyperketonemia (plasma BHBA $\geq 1,200 \mu m o l / L$ ), based on test-day results from 1,678 cows in early lactation (5-60 DIM). 
Table 3. Values (mean \pm SD) for cows with and without hyperketonemia and univariate association (logistic regression) with the occurrence of hyperketonemia (threshold $\geq 1,200 \mu \mathrm{mol} / \mathrm{L}$ ) for continuous test-day variables

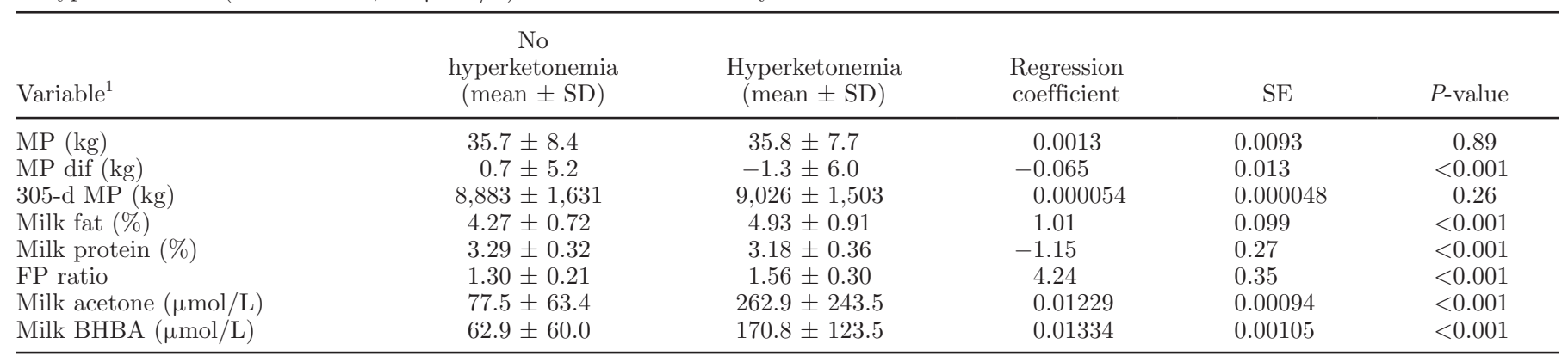

${ }^{1} \mathrm{MP}=$ milk production; $\mathrm{MP}$ dif $=$ actual - expected milk production; 305-d MP $=$ projected 305-d milk production; FP ratio $=$ fat-to-protein ratio.

optimal cutoff value were retested by wet chemistry analysis of milk acetone or milk BHBA to improve the specificity of the test procedure. The sensitivity, specificity, and predictive values of this serial test procedure are shown in Table 5. The specificity, sensitivity, and predictive values of the serial test procedure were higher compared with the performance of the diagnostic model alone at $95 \%$ specificity (Table 5).

Herd-level comparisons of true prevalence of hyperketonemia and apparent prevalence estimated by the diagnostic model (optimal cutoff value) are shown in Figure 3a. Herd-level comparisons for the model cutoff values at 90 or $95 \%$ specificity are shown in Figure $3 \mathrm{~b}$ and $3 \mathrm{c}$, respectively. Proportions of correctly estimated, underestimated, and overestimated herd prevalences for each of these 3 model settings are shown in Table 6. When a prevalence of above $10 \%$ was considered as alarm-level prevalence, then the model (optimal cutoff) notified $51.6 \%(\mathrm{n}=33)$ of healthy farms incorrectly as herds with hyperketonemia problems, whereas $3.7 \%$ (n $=2$ ) of problem herds remained unnoticed at the test day in this study. At the $90 \%$ specificity cutoff level,
$35.9 \%(\mathrm{n}=23)$ of healthy farms were incorrectly notified as herds with hyperketonemia problems, whereas $14.8 \%(\mathrm{n}=8)$ of problem herds were not detected. At the $95 \%$ specificity cutoff level, these proportions were $15.6 \%(\mathrm{n}=10)$ and $33.3 \%(\mathrm{n}=18)$, respectively. Herdlevel performance of the serial test procedures involving both wet chemical analyses are shown in Figure $4 \mathrm{a}$ and 4b. Especially wet chemical analysis of BHBA (Figure 4b) in positive test-day milk samples improved herd prevalence estimates of hyperketonemia in this study, as the proportion of incorrectly notified healthy farms was lower (12.5\% instead of $15.6 \%)$ and fewer problem herds were missed (20.4\% instead of $22.2 \%$ ) compared with wet chemical analysis of acetone.

\section{DISCUSSION}

The present study was performed to obtain a diagnostic model based on available test-day information, including FTIR predictions of milk acetone and milk BHBA, to improve the detection of hyperketonemia in early lactation cows. Cows were defined as hyperke-

Table 4. Model terms of final logistic regression model based on available test-day information (including milk acetone and milk BHBA concentration) for the detection of hyperketonemia (threshold $\geq 1,200 \mu \mathrm{mol} / \mathrm{L}$ ) in early lactation dairy cows ${ }^{1}$

\begin{tabular}{|c|c|c|c|}
\hline Variable & $\begin{array}{c}\text { Regression } \\
\text { coefficient }\end{array}$ & $\mathrm{SE}$ & $P$-value \\
\hline Intercept & -9.0976 & 0.8880 & $<0.001$ \\
\hline Parity 1 & Referent & & \\
\hline Parity 2 & -0.0549 & 0.3863 & 0.89 \\
\hline Parity 3 & 0.6899 & 0.3562 & 0.053 \\
\hline Parity $\geq 4$ & 1.3622 & 0.3195 & $<0.001$ \\
\hline Fall & Referent & & \\
\hline Winter & 0.1794 & 0.5427 & 0.74 \\
\hline Spring & 1.5146 & 0.5145 & 0.003 \\
\hline Summer & 1.1842 & 0.5083 & 0.020 \\
\hline Milk fat-to-protein ratio & 2.5336 & 0.5338 & $<0.001$ \\
\hline Milk acetone $(\mu \mathrm{mol} / \mathrm{L})$ & 0.01002 & 0.00147 & $<0.001$ \\
\hline Milk BHBA $(\mu \mathrm{mol} / \mathrm{L})^{\prime}$ & 0.00294 & 0.00166 & 0.077 \\
\hline
\end{tabular}

${ }^{1} \mathrm{~A}$ random herd effect was included in the model; mean herd variance $( \pm \mathrm{SD})$ was $1.7921 \pm 1.3387$. 
Table 5. Sensitivity, specificity, and predictive values of serial test procedures involving the diagnostic model in combination with confirmation of test-positive samples by wet chemistry analysis of milk acetone or milk BHBA concentrations to detect hyperketonemia (plasma BHBA $\geq 1,200 \mu \mathrm{mol} / \mathrm{L}$ ) in dairy cows

\begin{tabular}{lcc}
\hline Item & $\begin{array}{c}\text { Model }+ \text { milk } \\
\text { acetone }^{1}\end{array}$ & $\begin{array}{c}\text { Model }+ \text { milk } \\
\text { BHBA }^{1}\end{array}$ \\
\hline Cutoff value model, test 1 & 0.076 & 0.076 \\
Cutoff value milk analysis, test 2 $(\mu \mathrm{mol} / \mathrm{L})$ & 105.0 & 85.0 \\
Sensitivity [\% (95\% CI)] & $66.5(59.7-73.2)$ & $62.2(55.3-69.2)$ \\
Specificity [\% (95\% CI)] & $96.4(95.4-97.3)$ & $97.3(96.5-98.1)$ \\
Positive predictive value $(\%)$ & $69.8(63.1-76.6)$ & $74.5(67.7-81.3)$ \\
Negative predictive value $(\%)$ & $95.8(94.8-96.8)$ & $95.3(94.3-96.4)$ \\
\hline
\end{tabular}

${ }^{1}$ Milk acetone and milk BHBA concentrations were determined by chemical analysis after routine Fourier transform infrared (FTIR) analysis in test-day milk samples classified as hyperketonemic, with the diagnostic model applied at the optimal cutoff value.

tonemic when plasma BHBA concentrations equaled or exceeded $1,200 \mu \mathrm{mol} / \mathrm{L}$. The observed prevalence of hyperketonemia was $11.2 \%$, which is comparable with that in earlier studies (Nielen et al., 1994; Duffield et al., 1997; Geishauser et al., 2000).

Acetone and BHBA are currently routinely analyzed by FTIR spectroscopy in test-day milk samples in the Netherlands at no extra cost for the dairy farmer. van Knegsel et al. (2010) concluded that the practical applicability of these FTIR predictions as a single test was limited due to large numbers of false-positive test results. Compared with that study, overall accuracies

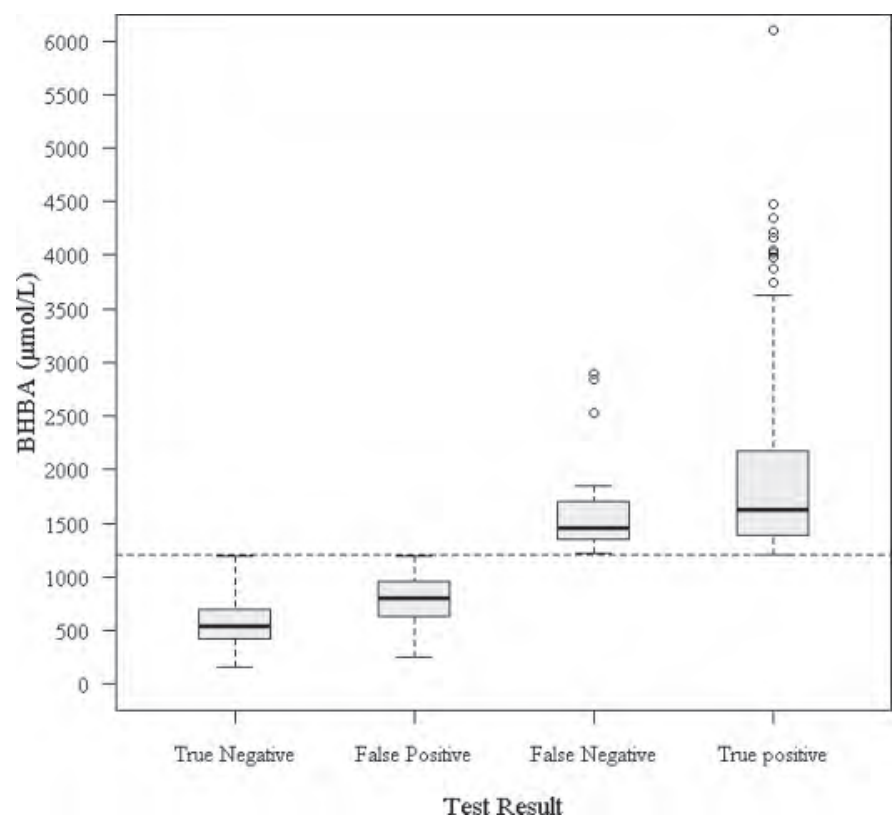

Figure 2. Plasma BHBA concentrations for cows with true-negative $(\mathrm{n}=1,248)$, false-positive $(\mathrm{n}=242)$, false-negative $(\mathrm{n}=33)$, or true-positive $(\mathrm{n}=155)$ test results, as assessed with the diagnostic model applied at the optimal cutoff value. Plasma BHBA $\geq 1,200$ $\mu \mathrm{mol} / \mathrm{L}$ (dashed line) was used to define hyperketonemia. Boxes represent median and interquartile range; whiskers include all cases except outliers (circles, values greater than 2 interquartile ranges from upper quartile). for milk acetone and milk BHBA to detect hyperketonemia in dairy cows were somewhat higher in the present study, but still inadequate for reliable hyperketonemia detection at test days. We, therefore, investigated whether detection of hyperketonemia could be improved by combination of test-day variables into a multivariate diagnostic model.

Univariate analysis showed that fat content, protein content, fat-to-protein ratio, acetone concentration, and BHBA concentration in test-day milk were significantly associated with the occurrence of hyperketonemia in this study. Milk production level at the test day was not associated with the presence of the disease. This is in contrast to previous studies, which reported increased ketone body concentrations in serum (Duffield et al., 2009) or milk (Dohoo and Martin, 1984; Miettinen and Setälä, 1993) to be associated with reduced test-day yields. Although a reduced milk production may be expected in hyperketonemic cows and certainly upon the occurrence of clinical ketosis (Østergaard and Gröhn, 1999), the absolute milk production at the test day was no indicator for the disease in this study. This may be due to higher risk of developing ketosis and associated milk production losses for higher-producing cows that also have a higher expected milk production than lower-producing cows at the test day. Also, cows may have been ketotic previous to the test day, which affected their test-day milk production.

For the present study, only information routinely available at test day was implemented in the diagnostic model. However, Nielsen et al. (2005) showed that, for example, BCS at calving and occurrence of other diseases could be used to predict the risk for ketosis in dairy cows. This information could also be used for hyperketonemia detection, provided that it becomes routinely available at test days (e.g., via the management program of the dairy farmer). In addition, cows with ketosis seemed to have decreased citrate concentrations (Baticz et al., 2002) and elevated oleic acid concentrations (Van Haelst et al., 2008) in milk compared 


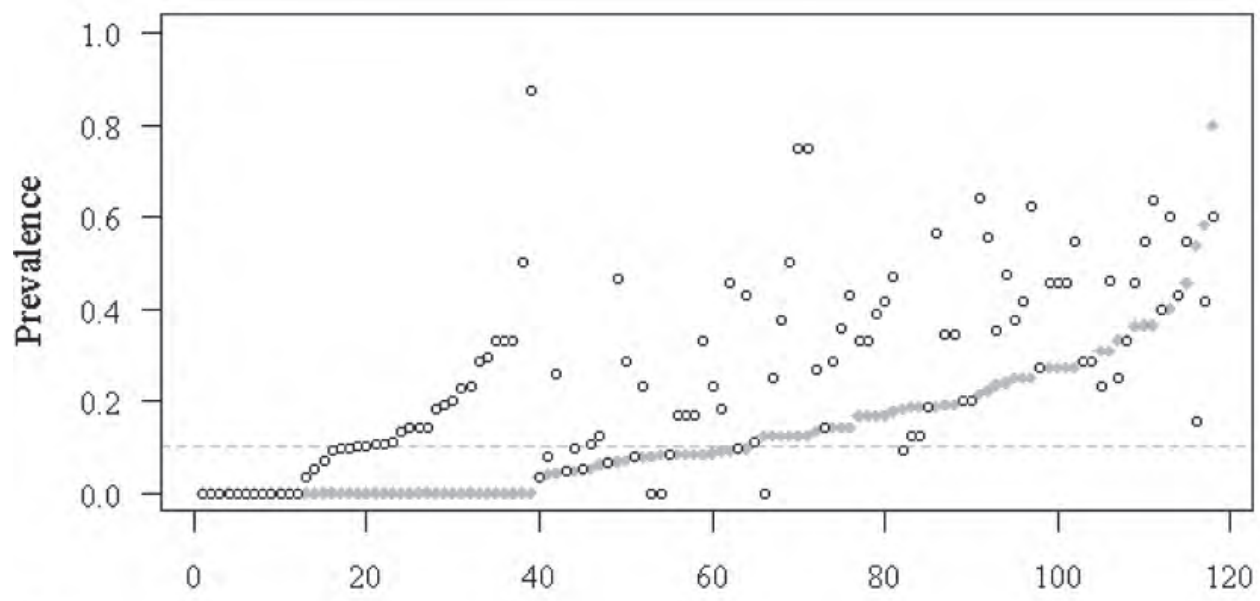

b

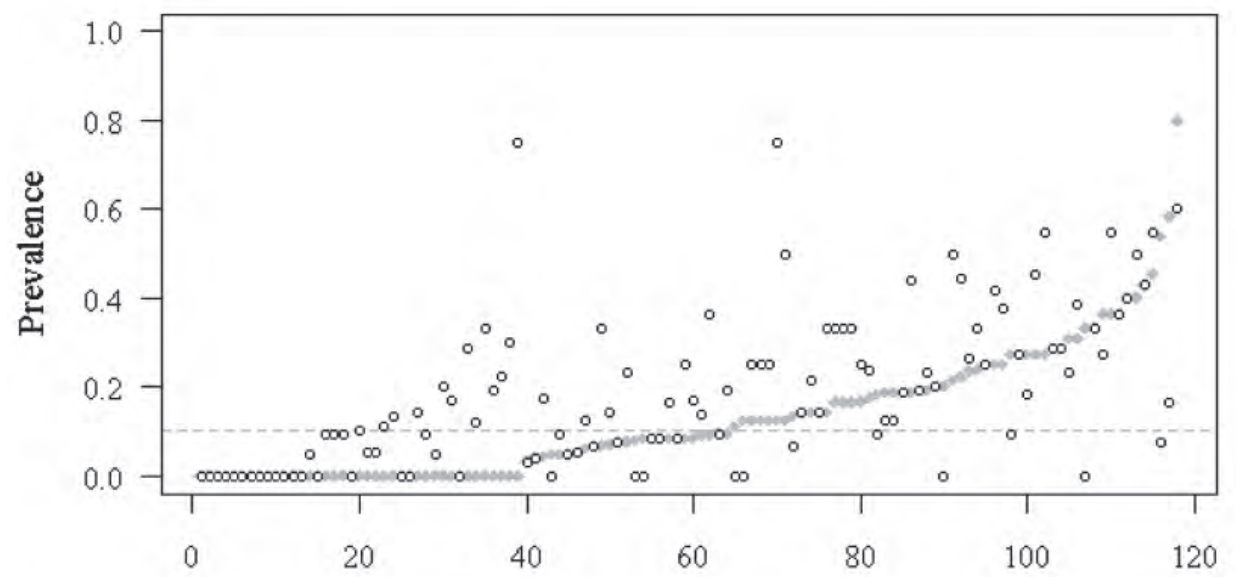

$\mathrm{c}$

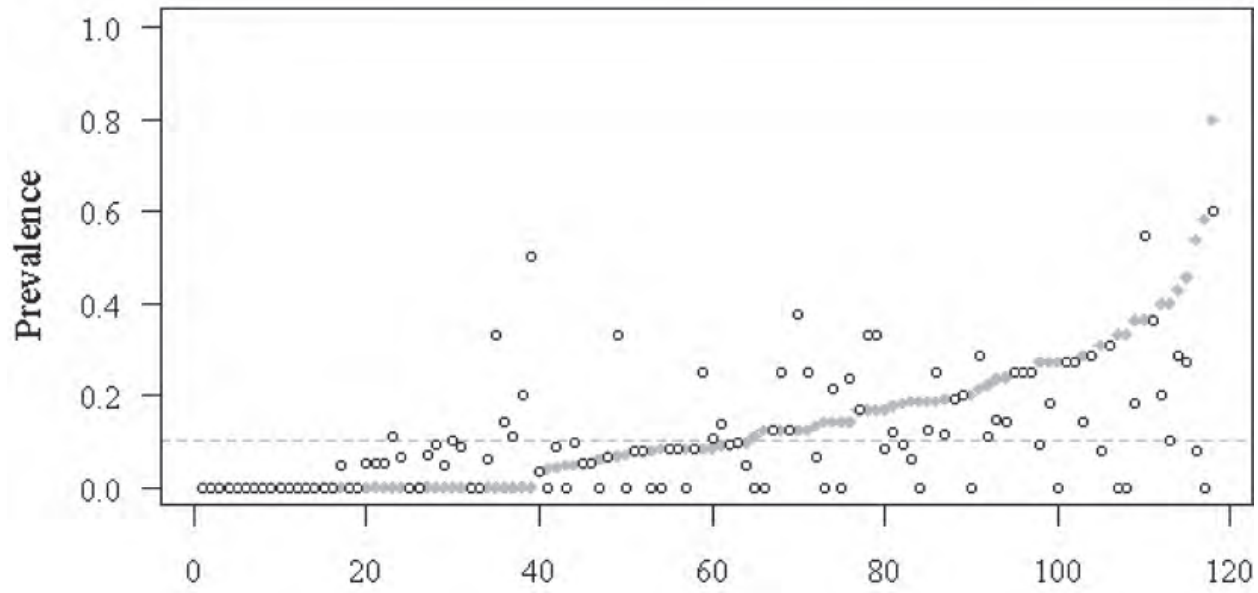

Farm

Figure 3. Herd-level comparisons of true prevalence, as measured by plasma BHBA concentrations (gray diamonds, farms ranked in order of increasing prevalence on x-axis), and apparent prevalence (white circles), as estimated from test-day information by the diagnostic model applied at the optimal cutoff value (a), at a cutoff corresponding to $90 \%$ specificity (b), and at a cutoff corresponding to $95 \%$ specificity (c) for the 118 Dutch dairy farms in this study. The gray dashed lines in the figures indicate the (arbitrary) alarm-level prevalence of $10 \%$. 
Table 6. Herd-level performance of the diagnostic model, applied at the optimal cutoff value, at cutoff values representing $90 \%$ or $95 \%$ specificity, or in combination with wet chemistry analysis of milk acetone or milk BHBA concentrations, as shown by the number and proportion of correctly estimated, underestimated, and overestimated herd prevalences in 118 Dutch dairy farms

\begin{tabular}{lccc}
\hline Item & $\begin{array}{c}\text { Correct } \\
\text { prevalence }\end{array}$ & $\begin{array}{c}\text { Underestimated } \\
\text { prevalence }\end{array}$ & $\begin{array}{c}\text { Overestimated } \\
\text { prevalence }\end{array}$ \\
\hline $\begin{array}{l}\text { Model, optimal cutoff } \\
\text { No. of farms (\%) }\end{array}$ & $30(25.4)$ & $11(9.3)$ & $77(65.3)$ \\
$\begin{array}{l}\text { Model, 90\% specificity } \\
\text { No. of farms (\%) } \\
\begin{array}{l}\text { Model, 95\% specificity } \\
\text { No. of farms (\%) }\end{array}\end{array}$ & $23(19.5)$ & $29(24.6)$ & $66(55.9)$ \\
$\begin{array}{l}\text { Model + milk acetone } \\
\text { No. of farms (\%) } \\
\begin{array}{l}\text { Model + milk BHBA } \\
\text { No. of farms (\%) }\end{array}\end{array}$ & $29(24.6)$ & $50(42.4)$ & $39(33.0)$ \\
\hline
\end{tabular}

${ }^{1}$ Milk acetone and milk BHBA concentrations were determined by chemical analysis after routine Fourier transform infrared (FTIR) analysis in test-day milk samples classified as hyperketonemic, with the diagnostic model applied at the optimal cutoff value.

with cows having plasma BHBA concentrations below the threshold. Fourier transform infrared spectroscopy analysis of such milk compounds may further improve herd monitoring for hyperketonemia at test days.

Parity, season, milk fat-to-protein ratio, milk acetone, and milk BHBA were included as predictive variables in our final diagnostic model. Although the model included season, the study design did not allow for a robust evaluation of the effect of season on the occurrence of hyperketonemia, as herds were only visited once in a particular season. The variable season was, however, contained in the final model, as herds were randomly selected throughout the year and approximately 30 herds were visited per season. Considerable variation in the probability of hyperketonemia for cows in the data set was explained by the random herd effect in the model. This suggests herd differences in the association between plasma BHBA concentrations and milk acetone and BHBA concentrations within cows. An explanation may be that timing of milk sampling, feeding and blood sampling was not identical on the different farms in the study. Genetic differences between cows in udder ketone body metabolism may also exist, which can influence excretion of ketone bodies from blood to milk.

The diagnostic model had a sensitivity of $82.4 \%$ and a specificity of $83.4 \%$ for the detection of hyperketonemia at the optimal cutoff value in this study. These are within the range of test characteristics observed for several cowside urine and milk tests for ketosis, as reviewed by Oetzel (2004). The model was also a better test for hyperketonemia than milk fat-to-protein ratio, which was until recently used in the Netherlands to detect cows with ketosis at test days. As a test for hyperketonemia, test-day milk fat-to-protein ratio had a sensitivity of $64.4 \%$ and a specificity of $76.4 \%$ in the current study (cutoff value 1.43, results not shown). Despite improved test characteristics compared with other tests, we would not recommend using the diagnostic model for the detection of individually diseased cows. The reason is that the test procedure is only performed on test days (every 3 to 6 wk upon choice of the farmer) and is not directly available (1-d lag in the Netherlands). Also, the low positive predicted value of the test result (given the average prevalence in this study) would result in unnecessary treatment of healthy cows. We, therefore, suggest relying on clinical signs and cowside testing for detection of clinical ketosis in individual cows.

The diagnostic model (optimal cutoff value) overestimated the prevalence of hyperketonemia in the majority of herds due to the high proportion of false-positive test results for individual cows in this study. For some herds, the relatively large differences between the observed prevalence and the estimated prevalence can also be caused by the low number of cows sampled at the test day, as 1 false test result has a relatively large effect on the estimated herd prevalence. At each farm, blood and milk was sampled from all cows between 5 and 60 DIM (census approach), which were, on average, 14 cows per farm. This number ranged, however, from 3 to 47 cows for individual farms, depending on farm size (average Dutch farm size is approximately 80 cows) and calving pattern. For smaller herds, test-day hyperketonemia prevalences may, therefore, be preferably interpreted when a larger number of fresh cows is sampled on consecutive test days (e.g., as a rolling average for a quarter or half of a year). Increasing the cutoff value of the model did not markedly improve the herd-level performance of the model. At the $95 \%$ specificity level, the prevalence of the disease was underestimated in a large proportion of herds. Combination of the diagnos- 


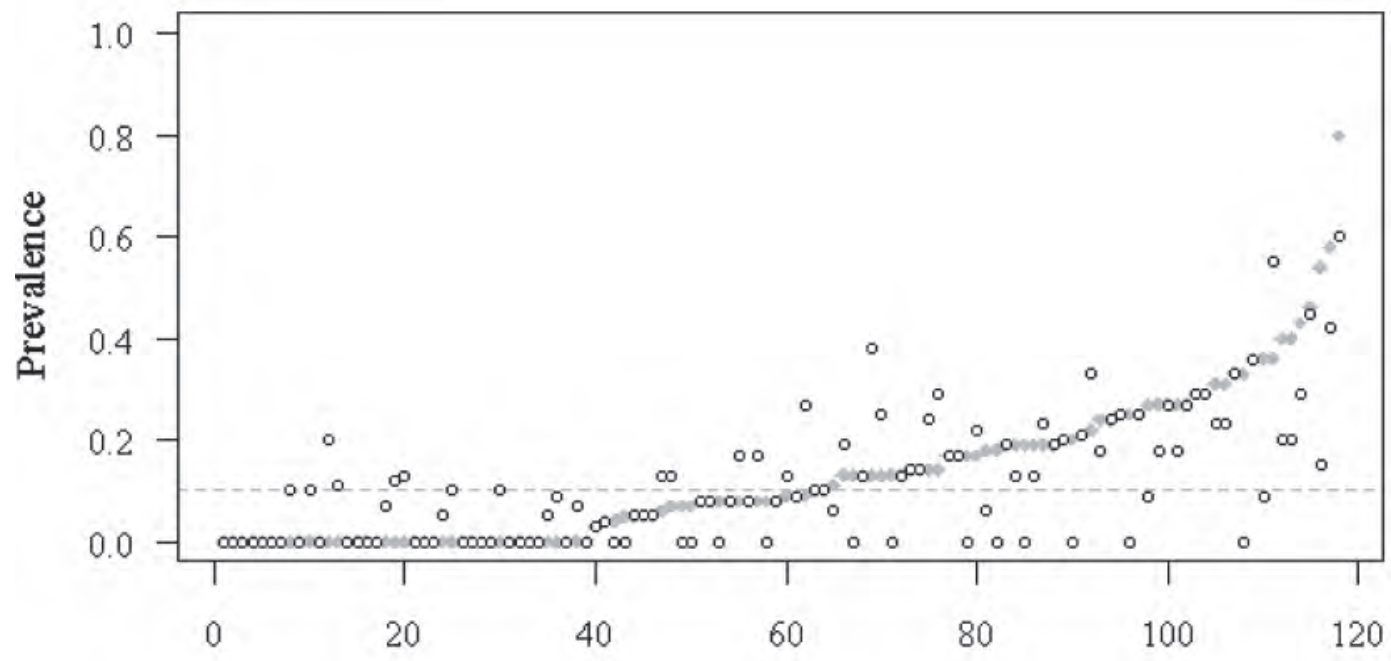

b

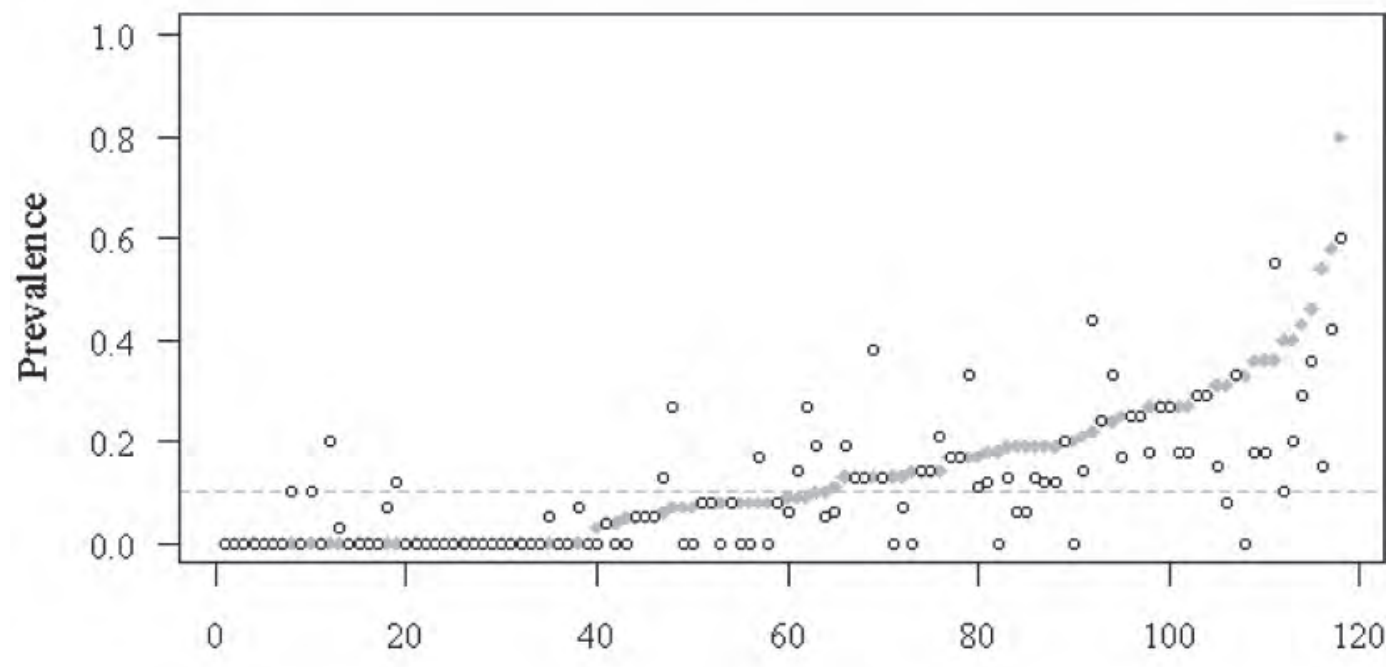

Farm

Figure 4. Herd-level comparisons of true prevalence, as measured by plasma BHBA concentrations (gray diamonds, farms ranked in order of increasing prevalence on X-axis), and apparent prevalence (white circles), as estimated with a serial test procedure involving the diagnostic model + wet chemical analysis of milk acetone (a) or the diagnostic model + wet chemical analysis of milk BHBA (b) for the 118 Dutch dairy farms in this study. The gray dashed lines in the figures indicate the (arbitrary) alarm-level prevalence of $10 \%$.

tic model with wet chemistry analysis of particularly milk BHBA concentrations in a selection of test-day samples improved herd prevalence estimates due to a higher specificity of the test procedure.

We additionally investigated whether prevalence estimates could be improved by applying the epidemiological principle that the true prevalence (TP) in a herd can be estimated from the apparent prevalence (AP) with any test with known sensitivity and specificity by the formula $\mathrm{TP}=(\mathrm{AP}+\mathrm{Sp}-1) /(\mathrm{Se}+\mathrm{Sp}-1)$, where Sp is specificity and Se is sensitivity (Dohoo et al., 2007). Herd prevalence estimates in our study, however, only improved when the true and apparent prevalence of a particular herd were comparable with the entire study population (results not shown). This principle may, therefore, have limited value for estimation of the wide range of occurring hyperketonemia prevalences in dairy herds. Alternatively, although the diagnostic model was developed and evaluated for cows between 5 and 60 DIM (representing the fresh group 
on test-day reports), restricting the test window for hyperketonemia to cows in the first $30 \mathrm{~d}$ postpartum may be considered. As the prevalence was higher in cows in this period $(16.8 \%)$ compared with the second month postpartum $(7.0 \%)$, this would reduce the number of false-positive test results and probably improve herd prevalence estimation on test days. Detection of a prevalence increase on farms would also improve with shorter test-day intervals, so that a larger proportion of cows would be sampled in this first $30 \mathrm{~d}$ after calving.

The strong point of the use of test-day information for hyperketonemia detection is that it is cheap and largely automated. Although test characteristics for individual cow testing are suboptimal, we showed that the diagnostic model allows a fair estimation of the herd prevalence of hyperketonemia in dairy herds. A hyperketonemia alarm-level prevalence of $10 \%$ was previously suggested by Oetzel (2004). Although it may be argued whether this represents a reasonable alarm level for our study with a hyperketonemia prevalence of only $7.0 \%$ in cows above 30 DIM, we illustratively used this alarm level to assess proportions of correctly classified farms with different model settings. In our opinion, detecting farms with hyperketonemia prevalences above the alarm level has the highest priority. Taking herd-level measures to prevent hyperketonemia in low-prevalence herds may be less of a problem, as these farms may even benefit from measures to optimize nutrition and management of peripartum dairy cows. The test procedure involving the diagnostic model in combination with wet chemistry analysis of milk BHBA in test-positive milk samples is, therefore, preferably used for herd-level testing for hyperketonemia. It correctly classified the vast majority of herds at a $10 \%$ alarm-level prevalence: $(118-19) / 118=84 \%$. Wet chemical analysis of testday milk samples, however, involves extra costs, which should be weighed against the option to measure blood BHBA concentrations of (a sample of) cows directly on the farm. If wet chemistry analysis of milk ketone bodies is not feasible, then the cutoff value corresponding to a specificity of $90 \%$ is probably the best option for hyperketonemia monitoring in practice.

\section{CONCLUSIONS}

We developed and evaluated a diagnostic model for the detection of hyperketonemia at test days in early lactation cows. The best-fitting model used information on parity, season, milk fat-to-protein ratio, and FTIR predictions of milk acetone and milk BHBA concentrations and had $82.4 \%$ sensitivity and $83.8 \%$ specificity at the optimal cutoff value. Confirmation of test-positive samples with wet chemistry analysis of milk acetone or milk BHBA concentrations improved the performance of the test procedure. Using a $10 \%$ alarm-level prevalence, $84 \%$ of herds were correctly classified by the diagnostic model in combination with wet chemistry analysis of milk BHBA. Misclassification of herds may occur with this method, in particular with a small number of cows sampled on the test day. For small dairy farms, we therefore suggest using prevalence estimates over several consecutive test days to evaluate feeding and management practices. The presented model is, in our opinion, suited for estimation of the herd prevalence of hyperketonemia on test days, especially when test-positive samples are confirmed with wet chemistry analysis of milk acetone or milk BHBA concentrations.

\section{ACKNOWLEDGMENTS}

The authors thank all dairy farmers that participated in the study. Lotte Roos (former master's student, Animal Science department, Wageningen University, Wageningen, the Netherlands) is gratefully acknowledged for her assistance in preparation and execution of farm visits.

\section{REFERENCES}

Andersson, L. 1988. Subclinical ketosis in dairy cows. Vet. Clin. North Am. Food Anim. Pract. 4:233-251.

Andersson, L., A. H. Gustafsson, and U. Emanuelson. 1991. Effect of hyperketonaemia and feeding on fertility in dairy cows. Theriogenology 36:521-536.

Baticz, O., S. Tömösközi, L. Vida, and T. Gaál. 2002. Relationship between concentration of citrate and ketone bodies in cow's milk. Acta Vet. Hung. 50:253-261.

Carrier, J., S. Stewart, S. Godden, J. Fetrow, and P. Rapnicki. 2004. Evaluation and use of three cowside tests for detection of subclinical ketosis in early postpartum cows. J. Dairy Sci. 87:3725-3735.

de Roos, A. P. W., H. J. C. M. van den Bijgaart, J. Hørlyk, and G. de Jong. 2007. Screening for subclinical ketosis in dairy cattle by Fourier transform infrared spectrometry. J. Dairy Sci. 90:1761-1766.

Dohoo, I., W. Martin, and H. Stryhn. 2007. Veterinary Epidemiologic Research. 2nd ed. AVC Inc., Charlottetown, PEI, Canada.

Dohoo, I. R., and S. W. Martin. 1984. Subclinical ketosis: Prevalence and associations with production and disease. Can. J. Comp. Med. 48:1-5.

Duffield, T. F., D. F. Kelton, K. E. Leslie, K. D. Lissemore, and J. H. Lumsden. 1997. Use of test day milk fat and milk protein to detect subclinical ketosis in dairy cattle in Ontario. Can. Vet. J. 38:713-718.

Duffield, T. F., K. D. Lissemore, B. W. McBride, and K. E. Leslie. 2009. Impact of hyperketonemia in early lactation dairy cows on health and production. J. Dairy Sci. 92:571-580.

Geishauser, T., K. Leslie, T. Duffield, and V. Edge. 1997. An evaluation of milk ketone tests for the prediction of left displaced abomasum in dairy cows. J. Dairy Sci. 80:3188-3192.

Geishauser, T., K. Leslie, J. Tenhag, and A. Bashiri. 2000. Evaluation of eight cow-side ketone tests in milk for detection of subclinical ketosis in dairy cows. J. Dairy Sci. 83:296-299.

Gustafsson, A. H., and U. Emanuelson. 1996. Milk acetone concentration as an indicator of hyperketonaemia in dairy cows: The critical value revised. Anim. Sci. 63:183-188.

Hansen, P. W. 1999. Screening of dairy cows for ketosis by use of infrared spectroscopy and multivariate calibration. J. Dairy Sci. 82:2005-2010. 
Heuer, C., H. J. Luinge, E. T. G. Lutz, Y. H. Schukken, J. H. van der Maas, H. Wilmink, and J. P. T. M. Noordhuizen. 2001. Determination of acetone in cow milk by Fourier transform infrared spectroscopy for the detection of subclinical ketosis. J. Dairy Sci. $84: 575-582$.

ISO. 1999. ISO 1211/IDF 1: Milk-Determination of fat contentGravimetric method (reference method). International Organization for Standardization, Geneva, Switzerland.

ISO. 2001. ISO 8968-1/IDF 20-1: Milk-Determination of nitrogen content-Part 1: Kjeldahl method. International Organization for Standardization, Geneva, Switzerland.

Iwersen, M., U. Falkenberg, R. Voigtsberger, D. Forderung, and W. Heuwieser. 2009. Evaluation of an electronic cowside test to detect subclinical ketosis in dairy cows. J. Dairy Sci. 92:2618-2624.

Jorritsma, R., S. J. C. Baldée, Y. H. Schukken, T. Wensing, and G. H. Wentink. 1998. Evaluation of a milk test for detection of subclinical ketosis. Vet. Q. 20:108-110.

LeBlanc, S. 2010. Monitoring metabolic health of dairy cattle in the transition period. J. Reprod. Dev. 56:S29-S35.

LeBlanc, S. J., K. E. Leslie, and T. F. Duffield. 2005. Metabolic predictors of displaced abomasum in dairy cattle. J. Dairy Sci. $88: 159-170$.

Miettinen, P. V. A., and J. J. Setälä. 1993. Relationships between subclinical ketosis, milk production and fertility in Finnish dairy cattle. Prev. Vet. Med. 17:1-8.

Nielen, M., M. G. Aarts, A. G. Jonkers, T. Wensing, and Y. H. Schukken. 1994. Evaluation of two cowside tests for the detection of subclinical ketosis in dairy cows. Can. Vet. J. 35:229-232.

Nielsen, N. I., N. C. Friggens, M. G. G. Chagunda, and K. L. Ingvartsen. 2005. Predicting risk of ketosis in dairy cows using in-line measurements of $\beta$-hydroxybutyrate: A biological model. J. Dairy Sci. 88:2441-2453.

Oetzel, G. R. 2004. Monitoring and testing dairy herds for metabolic disease. Vet. Clin. North Am. Food Anim. Pract. 20:651-674.

Østergaard, S., and Y. T. Gröhn. 1999. Effects of diseases on test day milk yield and body weight of dairy cows from Danish research herds. J. Dairy Sci. 82:1188-1201.

Robin, X., N. Turck, A. Hainard, N. Tiberti, F. Lisacek, J.-C. Sanchez, and M. Müller. 2011. pROC: An open-source package for R and $\mathrm{S}+$ to analyze and compare ROC curves. BMC Bioinformatics 12:77-84.

Seifi, H. A., S. J. LeBlanc, K. E. Leslie, and T. F. Duffield. 2011. Metabolic predictors of post-partum disease and culling risk in dairy cattle. Vet. J. 188:216-220.

Thrusfield, M., C. Ortega, I. de Blas, J. P. Noordhuizen, and K. Frankena. 2001. WIN EPISCOPE 2.0: Improved epidemiological software for veterinary medicine. Vet. Rec. 148:567-572.

Van Haelst, Y. N. T., A. Beeckman, A. T. M. Van Knegsel, and V. Fievez. 2008. Short communication: Elevated concentrations of oleic acid and long-chain fatty acids in milk fat of multiparous subclinical ketotic cows. J. Dairy Sci. 91:4683-4686.

van Knegsel, A. T. M., S. G. A. van der Drift, M. Horneman, A. P. W. de Roos, B. Kemp, and E. A. M. Graat. 2010. Short communication: Ketone body concentration in milk determined by Fourier transform infrared spectroscopy: Value for the detection of hyperketonemia in dairy cows. J. Dairy Sci. 93:3065-3069.

Walsh, R. B., J. S. Walton, D. F. Kelton, S. J. LeBlanc, K. E. Leslie, and T. F. Duffield. 2007. The effect of subclinical ketosis in early lactation on reproductive performance of postpartum dairy cows. J. Dairy Sci. 90:2788-2796. 